\title{
The effects of amino acid/protein supplementation in hemodialysis patients: study protocol for a systematic review and meta-analysis
}

Ryota Matsuzawa ${ }^{1 *}$ D, Shohei Yamamoto ${ }^{2,3}$, Yuta Suzuki ${ }^{2}$, Yoshifumi Abe $^{4}$, Manae Harada ${ }^{5}$, Takahiro Shimoda ${ }^{2}$, Keigo Imamura², Sachi Yamabe², Haruka Ito², Shun Yoshikoshi ${ }^{2}$ and Atsuhiko Matsunaga ${ }^{2}$

\begin{abstract}
Background: Multiple factors including older age, comorbidities, inflammation, metabolic acidosis, dialysis-related hypercatabolism and anabolic resistance of skeletal muscle, extraction of circulating amino acids through hemodialysis and inadequate dietary protein intake due to anorexia, and strictly limited dietary phosphorus intake are likely to contribute to the high prevalence of malnutrition and metabolic abnormalities, more aptly called protein-energy wasting, in patients on hemodialysis. The consensus from the International Society of Renal Nutritional and Metabolism states that nutritional supplementation is effective for replenishing protein and energy stores. Although we hypothesize that amino acid/protein supplementation can overcome the anabolic resistance of skeletal muscle tissue and attenuate or even prevent the accelerated loss of skeletal muscle mass and strength through nutritional status improvement in patients on hemodialysis, whether amino acid and/or protein administration is associated with improvements in these outcomes is unknown. The main objective of this study is to systematically review the impact of amino acid/protein supplementation on skeletal muscle mass, muscle strength, physical function, and quality of life in end-stage renal disease patients requiring hemodialysis.
\end{abstract}

Methods: Published randomized controlled trials (RCTs) assessing the effectiveness of amino acid/protein supplementation in hemodialysis patients with respect to body composition, muscle mass, muscle strength, physical function, and quality of life will be included. The bibliographic databases include MEDLINE, the Web of Science, the Cochrane Central Register of Controlled Trials, and Embase. The risk of bias of the included RCTs will be assessed using the Cochrane Collaboration's tool by two independent reviewers. The primary outcome will be skeletal muscle mass, muscle strength, and physical function, and the secondary outcome will be quality of life. This review protocol is reported according to the Preferred Reporting Items for Systematic Reviews and Meta-Analyses Protocol (PRISMA-P) 2015 checklist.

\footnotetext{
* Correspondence: ryota122560@gmail.com

'Department of Physical Therapy, School of Rehabilitation, Hyogo University of Health Sciences, 1-3-6 Minatojima, Chuo-ku, Kobe, Hyogo 650-8530, Japan Full list of author information is available at the end of the article
}

(c) The Author(s). 2020 Open Access This article is licensed under a Creative Commons Attribution 4.0 International License, which permits use, sharing, adaptation, distribution and reproduction in any medium or format, as long as you give appropriate credit to the original author(s) and the source, provide a link to the Creative Commons licence, and indicate if changes were made. The images or other third party material in this article are included in the article's Creative Commons licence, unless indicated otherwise in a credit line to the material. If material is not included in the article's Creative Commons licence and your intended use is not permitted by statutory regulation or exceeds the permitted use, you will need to obtain permission directly from the copyright holder. To view a copy of this licence, visit http://creativecommons.org/licenses/by/4.0/ The Creative Commons Public Domain Dedication waiver (http://creativecommons.org/publicdomain/zero/1.0/) applies to the data made available in this article, unless otherwise stated in a credit line to the data. 
(Continued from previous page)

Ethics and dissemination: Ethical approval is not required because this study does not include confidential personal data or involve patient interventions. This review is expected to inform readers on the effect of amino acid/protein supplementation in patients undergoing hemodialysis. The findings will be presented at conferences and submitted to a peer-reviewed journal for publication.

Trial registration: The trial registration number is (CRD42020181087), and the trial was registered on 5 July 2020.

Keywords: Protein energy wasting, Hemodialysis, Amino acid, Nutritional status, Nutrition therapy, Sarcopenia, Frailty

\section{Background}

An aging population and the increasing prevalence of noncommunicable diseases, such as diabetes, hypertension, and cardiovascular disease, have led to a worldwide increase in the rate of chronic kidney disease requiring renal replacement therapy [1]. In addition to older age and comorbidities, multiple factors, including inflammation, metabolic acidosis, dialysis-related hypercatabolism and anabolic resistance of skeletal muscle, extraction of circulating amino acids through hemodialysis and inadequate dietary protein intake due to anorexia, and strictly limited dietary phosphorus intake are likely to contribute to the high prevalence of malnutrition and metabolic abnormalities, more aptly called protein-energy wasting (PEW) [2], in patients on hemodialysis [3]. The prevalence rate of PEW among hemodialysis patients ranges from 28 to $56 \%$ [4] and predisposes such patients to frailty via loss of skeletal muscle mass and strength [5]. Frailty is considered highly prevalent with increasing age and to be a biologic syndrome of decreased reserve and resistance to stressors, causing vulnerability to adverse outcomes such as falls [6], poorer quality of life [7], reduced availability of transplants [8], hospitalizations [9], and mortality [10] in patients undergoing hemodialysis.

The consensus from the International Society of Renal Nutritional and Metabolism states that nutritional supplementation is effective in replenishing protein and energy stores [3]. Systematic reviews have recently shown that protein or amino acid supplementation was associated with an improvement in nutritional status by resulting in an increase in serum albumin $[11,12]$. We hypothesize that interventions consisting of amino acid/protein supplementation can overcome the anabolic resistance of skeletal muscle tissue and attenuate or even prevent the accelerated loss of skeletal muscle mass and strength through nutritional status improvement in patients on hemodialysis as described in a recent systematic review of elderly individuals without renal disease [13]. However, whether amino acid and/or protein administration is associated with improvements in the skeletal muscle mass, muscle strength, and physical function of chronic kidney disease patients undergoing hemodialysis is unknown.
The purpose of the present systematic review and meta-analysis is to provide an overview of the extant literature on interventions consisting of amino acid/protein supplementation in patients requiring hemodialysis therapy and to quantitatively examine the impact of the interventions on skeletal muscle mass, muscle strength, physical function, and quality of life. This systematic review and meta-analysis protocol is reported according to the Preferred Reporting Items for Systematic Reviews and MetaAnalyses Protocol (PRISMA-P) 2015 checklist [14, 15].

\section{Methods}

This systematic review and meta-analysis was registered with the International Prospective Register of Systematic Reviews (PROSPERO) (registration number: PROSPERO 2020: CRD42020181087). The study protocol will be conducted in accordance with the PRISMA guidelines.

\section{Literature review}

Our electronic database search included MEDLINE, the Web of Science, the Cochrane Central Register of Controlled Trials and Embase. We detail the electronic search strategy in Table 1 using MEDLINE as a sample. We used the following terms: $h^{*}$ emodialysis, dialysis, nutrition supplement, amino, protein*, randomized controlled trial, random allocation and so on. Additional file 1 shows the search strategy in more detail.

\section{Study selection/data management}

We will use EndNote X7 for Windows (Thompson Reuters, Philadelphia, Pennsylvania, USA) to manage literature records and Rayyan, which is a free, web-based tool developed and maintained by the Qatar Computing Research Institute, to screen the records. First, all search results, including information on authors, publication dates, journals, titles, and abstracts, will be downloaded and imported into an EndNote library for review, and duplicates will be removed. Second, remaining records will be imported to Rayyan, and two reviewers will independently screen the titles and abstracts to determine whether an article meets the inclusion criteria. Disagreements will be resolved by a third reviewer. Finally, two independent reviewers and a third reviewer will review the full text for eligibility. The study selection process is described in a flow chart (Fig. 1). 
Table 1 Search strategy to be used for MEDLINE electronic database

\begin{tabular}{|c|c|c|}
\hline \multirow{2}{*}{$\begin{array}{l}\text { Database } \\
\text { MEDLINE } \\
\text { (PubMed) }\end{array}$} & & \multirow{2}{*}{$\begin{array}{l}\text { Search strategy } \\
\text { Hemodialysis Units, Hospital[MeSH] OR Renal Dialysis[MeSH] }\end{array}$} \\
\hline & $\# 1$ & \\
\hline & $\# 2$ & 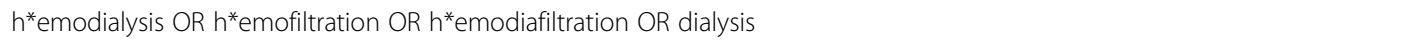 \\
\hline & $\# 3$ & end* AND (kidney disease* OR renal disease* OR renal insufficiency OR kidney failure OR renal failure) \\
\hline & \#4 & ESRF OR ESKF OR ESRD OR ESKD \\
\hline & $\# 5$ & \#1 OR \#2 OR \#3 OR \#4 \\
\hline & \#6 & $\begin{array}{l}\text { "nutrition supplement" OR "nutrition supplementary" OR "nutrition supplementation" OR "nutrition supplemental" OR } \\
\text { "nutrition supple-mentation" OR "Oral supplement" OR "Oral supplementary" OR "oral supplementation" OR "oral supplemental" } \\
\text { OR "oral supple-mentation" OR "nutrition support" OR "nutrition intervention" OR "nutrition status" OR "nutritional supplement" } \\
\text { OR "nutritional supplementary" OR "nutritional supplementation" OR "nutritional supplemental" OR "nutritional supple- } \\
\text { mentation" OR "nutritional support" OR "nutritional intervention" OR "nutritional status" OR "nutrient supplement" OR "nutrient } \\
\text { supplementary" OR "nutrient supplementation" OR "nutrient supplemental" OR "nutrient supple-mentation" OR "nutrient sup- } \\
\text { port" OR "nutrient intervention" OR "nutrient status" OR "nutritionally supplement" OR "nutritionally supplementary" OR "nutri- } \\
\text { tionally supplementation" OR "nutritionally supplemental" OR "nutritionally supple-mentation" OR "nutritionally support" OR } \\
\text { "nutritionally intervention" OR "nutritionally status" }\end{array}$ \\
\hline & $\# 7$ & amino OR "amino acids" OR protein* OR BCAA OR "branch chain amino acid" OR leucine* OR isoleucine* OR valine* \\
\hline & $\# 8$ & \#6 OR \#7 \\
\hline & $\# 9$ & Randomized Controlled Trial[MeSH] \\
\hline & $\# 10$ & Randomized Controlled Trials as Topic[MeSH] \\
\hline & $\# 11$ & Random Allocation[MeSH] \\
\hline & $\# 12$ & \#9 OR \#10 OR \#11 \\
\hline & $\# 13$ & \#5 AND \#8 AND \#12 \\
\hline
\end{tabular}
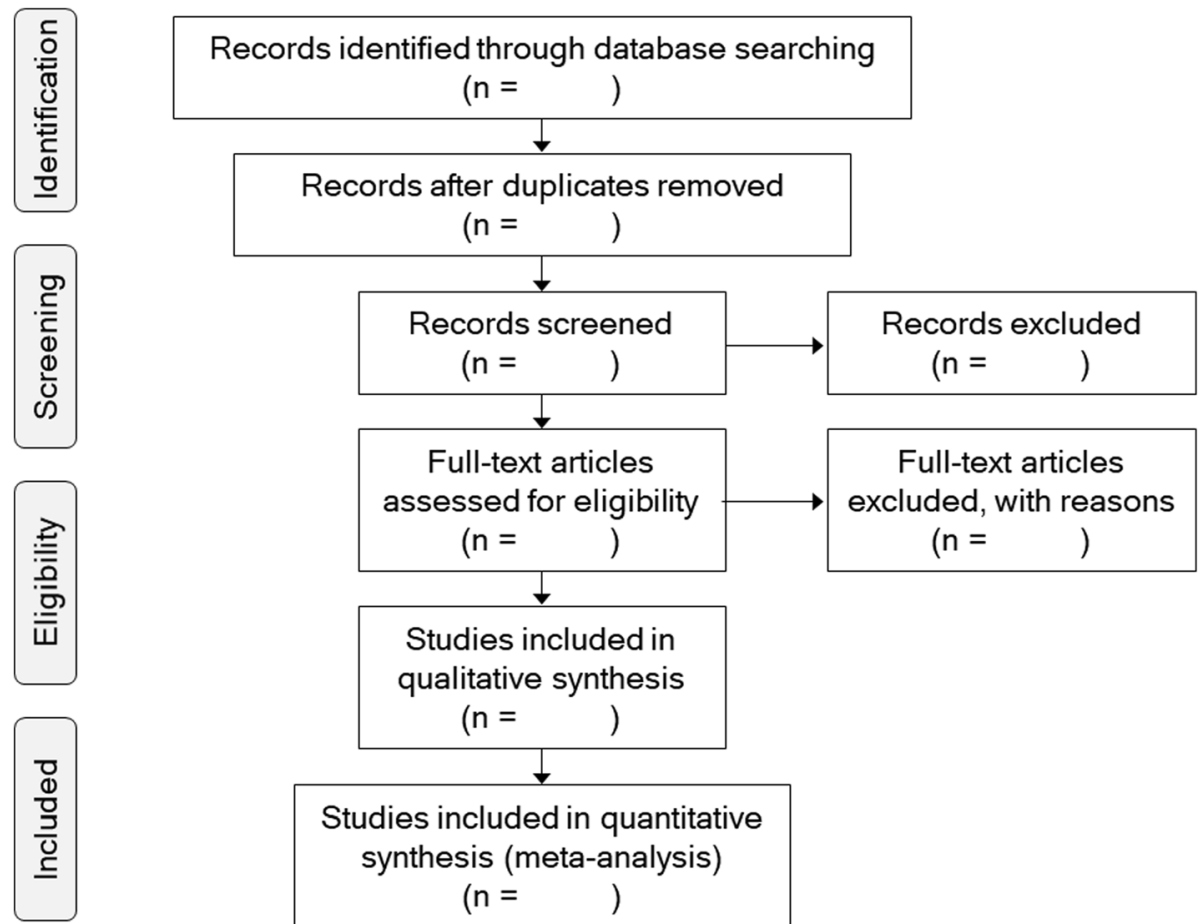

Studies included in qualitative synthesis

$(n=$ )

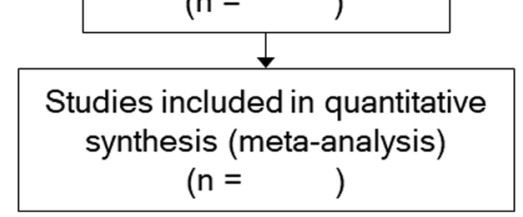

Fig. 1 Flow chart of the study selection 


\section{Inclusion/exclusion criteria}

We will include studies retrieved from our literature search that meet the following criteria:

1. Language: Published in English.

2. Participants: Patients aged at least 18 years with chronic kidney disease and undergoing hemodialysis therapy will be included. Patients under 18 years or those undergoing any other renal replacement therapy will be excluded. Patients affected by acute kidney failure will also be excluded.

3. Study design: Only randomized controlled trials (RCTs) evaluating the effects of nutritional interventions on lean body mass, skeletal muscle mass, muscle strength, physical function, or quality of life will be included in the present study. Reviews, opinion papers, letters, meeting abstracts, and any publications without primary data or an explicit description of the methods will be excluded.

4. Interventions: Oral/parenteral administration of amino acids and/or proteins with and without exercise interventions including resistance training, aerobic exercise, or combined exercise. Studies of dietary advice alone will not be included.

5. Controls: Placebo, usual care, or exercise interventions without any nutritional support.

6. Outcomes: Skeletal muscle mass (bioelectrical impedance analysis, dual-energy X-ray absorptiometry, computed tomography, and magnetic resonance imaging), lower extremity muscle strength (leg extension [Biodex]), physical function (walking ability [gait speed, the shuttle walk test, and 6-min walking distance], chair stands, and the timed up and go test), exercise capacity (peak oxygen intake), quality of life (the Medical Outcomes Study 12- or 36-Item Instrument Short Form Health Survey), and all-cause and cause-specific mortality.

7. Others: If duplicate publications of the same study or papers published in more than one journal are retrieved, the most comprehensive report will be used.

\section{Data extraction}

Relevant study characteristics and clinical outcome measures will be extracted. The data extracted from RCTs will include (1) author names, (2) publication year and journal name, (3) study design, (4) intervention duration, (5) study participants, (6) sample size of the intervention and control groups, (7) age, (8) dialysis vintage, (9) nutritional status, (10) the intervention modality in the treatment group, (11) the frequency of interventions, (12) the intervention modality in the control group, (13) compliance with interventions, and (14) outcome measures obtained (Table 2).

\section{Statistical analysis}

Our primary outcomes will be skeletal muscle mass, muscle strength, and physical function. The secondary outcome will be quality of life. Outcome definitions will be based on those used in the included studies. Subgroup analyses will be carried out by comparing treatment effects (i) between amino acid/protein supplementation and amino acid/protein supplementation plus exercise intervention groups, (ii) between oral and parenteral administration groups, and (iii) between studies including well-nourished (serum albu$\min >3.5 \mathrm{~g} / \mathrm{dL}$ ) and less well-nourished patients (serum albumin $\leq 3.5 \mathrm{~g} / \mathrm{dL}$ ) $[16,17]$.

Our statistical analysis strategy will involve identifying the average absolute changes in included patient measures from baseline to the end point (including 95\% CIs) in the intervention and control groups. Effect consistency across studies will be assessed with the $I^{2}$ statistic [18]. $I^{2}$ statistic values $>25 \%$ and $50 \%$ are considered indicators of moderate and substantial heterogeneity, respectively. As a result of the expected clinical heterogeneity between studies, we will use the randomeffect model as the default method of analysis because the alternative, the fixed-effect model, assumes that the true treatment effect in each trial is the same and that observed differences are due to chance. Publication bias will be assessed by plotting the inverse of the SEs of the

Table 2 Summary of findings for included randomized controlled trials

\begin{tabular}{|c|c|c|c|c|c|c|c|}
\hline References & $\begin{array}{l}\text { Study design } \\
\text { and duration }\end{array}$ & Study participants & $\begin{array}{l}\text { Sample size } \\
\text { (age, female sex, } \\
\text { dialysis vintage, } \\
\text { serum albumin, } \\
\text { and BMI) }\end{array}$ & $\begin{array}{l}\text { Intervention } \\
\text { modality in the } \\
\text { treatment group }\end{array}$ & $\begin{array}{l}\text { Frequency of } \\
\text { the intervention }\end{array}$ & $\begin{array}{l}\text { Intervention } \\
\text { modality in } \\
\text { the control group }\end{array}$ & $\begin{array}{l}\text { Outcome } \\
\text { measures }\end{array}$ \\
\hline
\end{tabular}

RCT 1

RCT 2

$\mathrm{RCT} 3$

RCT 4

RCT 5 
effect estimates using funnel plots, to explore symmetry, which will be assessed visually and with Egger's regression test [19]. Analysis will be conducted using $R$ version 3.30 ( $R$ Foundation for Statistical Computing, Vienna, Austria) and Stata version 16.0 (StataCorp LLC, College Station, TX). In all analyses, $P<0.05$ will be indicative of statistical significance. Two reviewers will independently assess the risk of bias of the studies using the Cochrane Collaboration tool, which consists of the following items: random sequence generation, allocation concealment, participant and personnel blinding, outcome assessment blinding, incomplete outcome data, selective reporting, and other sources of bias.

\section{Ethics and dissemination plans}

No ethical approval is required because this study does not include confidential personal data and does not involve patient interventions. This review is expected to determine the efficacy of amino acid/protein supplementation in patients undergoing hemodialysis. The findings will be presented at conferences and submitted to a peer-reviewed journal for publication.

\section{Supplementary information}

Supplementary information accompanies this paper at https://doi.org/10. 1186/s41100-020-00287-8.

Additional file 1. Search strategy.

\section{Abbreviations}

PEW: Protein-energy wasting; PRISMA-P: Preferred Reporting Items for Systematic Reviews and Meta-Analyses Protocol; PROSPERO: International Prospective Register of Systematic Reviews; RCTs: Randomized controlled trials

\section{Acknowledgements}

Not applicable.

\section{Authors' contributions}

RM, SY, and AM conceived and designed the protocol. RM, YS, and YA developed the search strategy and pilot searched the database. YA, MH, TS, $\mathrm{KI}, \mathrm{HI}$, and SY contributed to the development of the review protocol, the selection criteria, the risk of bias assessment strategy, and the data extraction criteria. All the authors critically revised and commented on the intellectual content of this manuscript, and all authors read and approved the final version of this manuscript.

\section{Funding}

This study is supported by JSPS KAKENHI (grant number 20 K19332).

\section{Availability of data and materials}

Not applicable.

\section{Ethics approval and consent to participate}

No ethical approval is required because this study does not include confidential personal data and does not involve patient intervention. This review is expected to determine the efficacy of amino acid/protein supplementation in patients undergoing hemodialysis. The findings will be presented at conferences and submitted to a peer-reviewed journal for publication.

\section{Consent for publication}

The authors consent to publication of the entire text of this dissertation.

\section{Competing interests}

The authors declare that they have no competing interests.

\section{Author details}

${ }^{1}$ Department of Physical Therapy, School of Rehabilitation, Hyogo University of Health Sciences, 1-3-6 Minatojima, Chuo-ku, Kobe, Hyogo 650-8530, Japan. ${ }^{2}$ Department of Rehabilitation Sciences, Kitasato University Graduate School of Medical Sciences, Sagamihara, Japan. ${ }^{3}$ Department of Epidemiology and Prevention, Center for Clinical Sciences, National Center for Global Health and Medicine, Tokyo, Japan. ${ }^{4}$ Division of Rehabilitation, Mitsui Memorial Hospital, Tokyo, Japan. ${ }^{5}$ Department of Rehabilitation, Sagami Circulatory Organ Clinic, Sagamihara, Japan.

Received: 27 April 2020 Accepted: 11 August 2020

Published online: 31 August 2020

\section{References}

1. Hamer RA, El Nahas AM. The burden of chronic kidney disease. BMJ. 2006; 332(7541):563-4.

2. Hendriks FK, Smeets JSJ, van der Sande FM, Kooman JP, van Loon LJC. Dietary protein and physical activity interventions to support muscle maintenance in end-stage renal disease patients on hemodialysis. Nutrients. 2019;11(12):2972.

3. Ikizler TA, Cano NJ, Franch H, Fouque D, Himmelfarb J, Kalantar-Zadeh $\mathrm{K}$, et al. Prevention and treatment of protein energy wasting in chronic kidney disease patients: a consensus statement by the International Society of Renal Nutrition and Metabolism. Kidney Int. 2013;84(6):1096-107.

4. Carrero JJ, Thomas F, Nagy K, Arogundade F, Avesani CM, Chan M, et al. Global prevalence of protein-energy wasting in kidney disease: a metaanalysis of contemporary observational studies from the International Society of Renal Nutrition and Metabolism. J Ren Nutr. 2018;28(6):380-92.

5. Carrero JJ, Stenvinkel P, Cuppari L, Ikizler TA, Kalantar-Zadeh K, Kaysen G, et al. Etiology of the protein-energy wasting syndrome in chronic kidney disease: a consensus statement from the International Society of Renal Nutrition and Metabolism (ISRNM). J Ren Nutr. 2013;23(2):77-90.

6. Delgado C, Shieh S, Grimes B, Chertow GM, Dalrymple LS, Kaysen GA, et al. Association of self-reported frailty with falls and fractures among patients new to dialysis. Am J Nephrol. 2015;42(2):134-40.

7. McAdams-DeMarco MA, Ying H, Olorundare I, King EA, Desai N, Dagher N, et al. Frailty and health-related quality of life in end stage renal disease patients of all ages. J Frailty Aging. 2016;5(3):174-9.

8. Haugen $C E$, Chu NM, Ying H, Warsame F, Holscher CM, Desai NM, et al. Frailty and access to kidney transplantation. Clin J Am Soc Nephrol. 2019; 14(4):576-82.

9. McAdams-DeMarco MA, Law A, Salter ML, Boyarsky B, Gimenez L, Jaar BG, et al. Frailty as a novel predictor of mortality and hospitalization in individuals of all ages undergoing hemodialysis. J Am Geriatr Soc. 2013; 61(6):896-901.

10. Johansen KL, Delgado C, Kaysen GA, Chertow GM, Chiang J, Dalrymple LS, et al. Frailty among patients receiving hemodialysis: evolution of components and associations with mortality. J Gerontol A Biol Sci Med Sci. 2019;74(3):380-6.

11. Liu PJ, Ma F, Wang QY, He SL. The effects of oral nutritional supplements in patients with maintenance dialysis therapy: a systematic review and metaanalysis of randomized clinical trials. PLoS One. 2018;13(9):e0203706.

12. Mah JY, Choy SW, Roberts MA, Desai AM, Corken M, Gwini SM, et al. Oral protein-based supplements versus placebo or no treatment for people with chronic kidney disease requiring dialysis. Cochrane Database Syst Rev. 2020; 5:CD012616

13. Cheng H, Kong J, Underwood C, Petocz P, Hirani V, Dawson B, et al. Systematic review and meta-analysis of the effect of protein and amino acid supplements in older adults with acute or chronic conditions. Br J Nutr. 2018:119(5):527-42.

14. Shamseer L, Moher D, Clarke M, Ghersi D, Liberati A, Petticrew M, et al. Preferred reporting items for systematic review and meta-analysis protocols (PRISMA-P) 2015: elaboration and explanation. BMJ. 2015;349:97647. 
15. Moher D, Shamseer L, Clarke M, Ghersi D, Liberati A, Petticrew M, et al. Preferred reporting items for systematic review and meta-analysis protocols (PRISMA-P) 2015 statement. Syst Rev. 2015:4:1.

16. Bolasco P, Caria S, Cupisti A, Secci R, Saverio DF. A novel amino acids oral supplementation in hemodialysis patients: a pilot study. Ren Fail. 2011;33(1): $1-5$.

17. Hiroshige K, Sonta T, Suda T, Kanegae K, Ohtani A. Oral supplementation of branched-chain amino acid improves nutritional status in elderly patients on chronic haemodialysis. Nephrol Dial Transplant. 2001;16(9):1856-62.

18. Higgins JP, Thompson SG, Deeks JJ, Altman DG. Measuring inconsistency in meta-analyses. BMJ. 2003;327(7414):557-60.

19. Egger M, Davey Smith G, Schneider M, Minder C. Bias in meta-analysis detected by a simple, graphical test. BMJ. 1997;315(7109):629-34.

\section{Publisher's Note}

Springer Nature remains neutral with regard to jurisdictional claims in published maps and institutional affiliations.

Ready to submit your research? Choose BMC and benefit from:

- fast, convenient online submission

- thorough peer review by experienced researchers in your field

- rapid publication on acceptance

- support for research data, including large and complex data types

- gold Open Access which fosters wider collaboration and increased citations

- maximum visibility for your research: over $100 \mathrm{M}$ website views per year

At BMC, research is always in progress.

Learn more biomedcentral.com/submissions 